\title{
USABILITY GUIDELINES FOR USABLE USER INTERFACE
}

\author{
Fourcan Karim Mazumder ${ }^{1}$, Utpal Kanti Das ${ }^{2}$ \\ ${ }^{1}$ Senior Lecturer, CSE, International University of Business Agriculture and Technology, Dhaka, Bangladesh \\ ${ }^{2}$ Associate Professor, CSE, International University of Business Agriculture and Technology, Dhaka, Bangladesh
}

\begin{abstract}
People can access computer by the help of Human-Computer Interaction (HCI) assistance. In Human-Computer Interaction (HCI) field, usability is the important substance. If we assume usability substance delayed or at last for system development which will become so expensive to get usable system. So that we need to think usability fact from the beginning of the system development cycle. This research is about the way how to design and develop usable user interface system. Design rules and principles are the effective means to design usable system. These rules provide the designers assistance to improve the usability of a system while designing. Usability rules and principles need to apply during design time of the system to produce best usable system.
\end{abstract}

Keywords: Usability, Golden rules, User interface, Heuristics

\section{INTRODUCTION}

Usability plays an important role for software development in Human-Computer Interaction (HCI) field. The motivation for applying usability when developing software system is to increase user satisfaction, efficiency, productivity, consequently. The usability goal is to help the systems users to perform their tasks. Also usability is helpful for users who can't effort to spend long time to know the system and less computer literate. Users not like to accept the system if the systems is less usable. To meet the user requirements is the main objective of software development. So the software development organization will loss the market if failure to provide the proper usability of the software. On the other hand proper usability of the software system will reduce the support costs. Usability relates how the system interacts with users. User interface is the visible part of the systems such as buttons, pull-down menus, checkboxes, background color, and so forth. User interaction is the coordination of the information exchange between the system and the user. So interaction design is not just designing the visible part of the user interface but also designing the rest of the system. Designers should apply the appropriate design rules and principles for systems usability. Designers get the direction to promote the usability of the system by following usability rules and principles (Dix et al., 2004). The objective of this research is to design and develop usable user interface by utilizing usability principles and rules.

\section{HUMAN-COMPUTER INTERACTION}

The term Human-Computer Interaction has been used from 1980's but it has more established roots. The study of human performance started at the beginning of the last century in factories on manual task. The Second World War introduced to learn the interaction between human and machine which was each side strove to produce effective weapons systems. Ergonomics Research Society in 1949 was established based on these concepts. Ergonomics primarily concerned with the characteristics of machines and systems and how these effect with user performance. Human factors integrate these issues which are often used interchangeably. Both of these issues indicated the user performance with any systems such as mechanical, manual or computer. As computer use increasing more, researchers are starting to study the interaction between people and computer concerning with physiological and theoretical aspects. First time it was started with the name of manmachine interaction, but after considering the particular interest of computer and user population, this became human-computer interaction (Dix et al., 2004). ACM SIGCHI defines HCI as: "Human-computer interaction is a discipline concerned with the design, evaluation and implementation of interactive computing systems for human use and with the study of major phenomena surrounding them" (Hewett et al., 2004). Olson and Olson (2003) termed Human-computer interaction as the study of how persons interact with computing technology. They mentioned two significant aspects of HCI such as design of computer systems and evaluation of systems. They highlighted numerous levels of analysis for evaluation like the individual, the group, the organization, and societal sector or the industry (Zhang et al., 2004).

HCI concept consists of three components such as Human which means persons who interact with the system. It may be individuals or groups of people. Computer means the device or computer that is interacted with. Devices beyond the desktop computer for example cell phone, car, PDA, ATM and door lock etc. also include in this category. Interaction means sharing of information between the human and the computer. For example people giving an input id and password into a computer system to login. Computer returns an output as displaying the welcome massage and home page of that system to use if persons id and password is right (Hong, 2006). HCI is a multidisciplinary subject. But computer science and system design is the central concern of HCI. Computer science is able to build necessary technology and HCI is involved to 
build usable and safe technology. In system design HCI engages for design, implementation and evaluation of interactive systems based on user's task. Physiology and cognitive science can provide user's cognitive and problem solving skills, user's perceptual for HCI. Ergonomics can provide user's physical capability; sociology can help to understand the wider context of the interactions for HCI (Dix et al., 2004).

\section{INTERACTION DESIGN}

Interaction design means designing interactive products to assist persons in their daily life. Interaction design is about producing user understanding that extend user work, communicate and interact. There are many fields for interaction design such as architectural design, graphic design, industrial design, computer system and software design. Four basic activities are involves in the process of interaction design such as identify needs and establishing requirements, developing alternative design to meet those requirement, building interactive version of designs, evaluating the building products (Preece et al., 2002).

The main objectives of interaction design are usability goals and user experience goals (Preece et al., 2002). Interaction designer should hold the following key attitude to design interaction (Saffer, 2007):

Focusing on User: Designers should supports end-users because basically users like to give priority for their task and to achieve their goals. Designers know that user don't care how the company makes a product.

Finding Alternative: Designing is about creating alternative options and solutions, it is not about choosing from multiple options.

Using Prototype: Designers use prototyping for their solution which means building models to test the solutions. Sometimes designers use several prototypes for a single solution.

Collaboration and Addressing Constraints: Sometimes designers work alone. To produce items, they needs resources and resources come with their own constrain. To meet the business goal, designers should compromise with team mates because designing is always a team effort.

Creating Appropriate Solution: Designers are producing the appropriate solutions for a specific project. They can use their experience and solutions to other project but they cannot exactly copy their solution to other project.

Drawing on Wide Range of Influences: Designing involves many subject areas such as psychology, ergonomics, economics, engineering, architecture, computer science and so on. So designers can get multidisciplinary ideas for solutions.

Incorporating Emotion: In design, to produce appropriate choice emotion is important logic because without emotion product becomes lifeless. In design decision, emotion should be considerately.

To design user satisfied Human-computer interaction, usability plays very important. Usability is the ease of use and acceptability of the systems for a specific user in a specific task environment. Acceptability effects whether the system is used and ease of use effects user satisfaction and performance (Holzinger et al., 2005). Usability is a most important part of human-computer interaction and plays a major role in software development. To improve the usability of software and devices, many usability techniques and methods has developed (Nichols et al., 2003). Usability is not a new idea, it has established from early 1970's to measure systems quality (Lozano et al., 2004).

\section{USABILITY}

The International Standard Organization (ISO) defines usability of a product as the extent so that user can use the product to achieve their goals with effectiveness, efficiency and satisfaction. Usability has five quality attributes such as learnability, memorability, efficiency, errors, and user satisfaction. One attribute might be more critical than another which is depends on the type of applications (Scholtz, 2004). Nielsen defines usability as a quality attribute so that improving ease-of-use during the design process (Nielsen, 2003). We can define quality attributes as the following way:

Learnability: This indicates how easy user can learn the main system functionality and achieve skill to do the job (Nielsen, 2003).

Efficiency: After learn the system, how fast users can perform their task using the systems (Nielsen, 2003).

Memorability: This reflects that how well user reestablished proficiency with the system functionality after come back a time period gap (Nielsen, 2003). Memorability is very important for irregular users to be able to use the system without getting the learning curve again. This feature helps the users to remember the system works after a period of use gap (Feree et al., 2001).

Errors: This address the number of error user make and how easily they can recover it (Nielsen, 2003).

Satisfaction: This is very important for usability of a system. It indicates that user is pleasant to use the system or not (Nielsen, 2003).

\section{USABILITY RULES AND PRINCIPLES}

We should follow design rules and principles for designing and evaluating user interface. Usability rules and principles give the direction to the designer to produce usable systems. There are so many principles and guidelines are available to produce usable interface. But all of these rules need to be simpler and track down in a particular point. Many advocates has presented a set of golden rules or heuristics which are used to provide useful summery of design advice 
and help to produce better usable systems. Amongst so many rules, Shneiderman's eight golden rules, Nielsen's ten heuristics are very useful and well-known (Dix et al., 2004). Also Gestalt principles are very useful for visual perception of interface design. These three are mentions as bellow:

\subsection{Shneiderman's Eight Golden Rules}

1. Strive for Consistency: All actions such as layout, terminology, command use, sequences and so on should maintain consistent sequences.

2. Enable Frequent Users to use Shortcuts: There are so many shortcuts such as macros, special key sequences, abbreviations which are use to regular action very quickly.

3. Offer Informative Feedback: System feedback is very important for all kinds of actions. So for all user action, system should provide proper feedback.

4. Design Dialog to Yield Closure: So that after completion their task user will knows when they have completed their task.

5. Offer Simple Error Handling: Design the system like the user cannot make a big error. So that user is prevented to make mistake and provide instruction to recover from error.

6. Permit Easy Reversal of Actions: So that user will know they can always return to the previous stage which is helpful to encourage exploration.

7. Support Internal Locus of Control: Design the system in such a way that experienced operator desires that they are in charge of the system and the system responds to their actions.

8. Reduce Short-Term Memory Load: It is possible by combining multiple page display, keeping displays simple, facilitate time to learn action sequences (Dix et al., 2004).

\subsection{Nielsen's Usability Heuristics}

1. Visibility of System Status: System should always inform the users what's going on using proper time feedback. User should know what's going on and what his next task is.

2. Match between System and the Real World: User comes from different background and different language. So system should use user's friendly language and concepts.

3. User Control and Freedom: All user want freedom and control of the visiting site. Sometimes user does the mistake and wants to emergency exit from the site. So system should provide previous, next, home button for user control.

4. Consistency and Standards: Proper standards and consistency is important to all sites. It is important to avoid user doubt if different word, situation or action means the same thing.
5. Help Users Recognize, Diagnose, and Recover from Errors: Provide user understandable language to explain the problem and the way to recover it.

6. Error Prevention: User can make error very easily so provide appropriate action to prevent error whether possible.

7. Recognition rather than Recall: Provide action, object, and options visible because user not likes to remember information from one part to another part of the site.

8. Flexibility and Efficiency of Use: Design the site in such a way that it can be used efficiently. Some accelerator use to speed up the interaction for the expert user.

9. Aesthetic and Minimalist Design: Dialogues on the web should contain core information only rather than irrelevant information.

10. Help and Documentation: Provides help in a set of steps so that user can easily follow that and provide easily searchable information (Preece et al., 2002).

\subsection{Gestalt Principles of Visual Perception}

Gestalt principles describe how we can perceive objects in our environments. These principles help us to identify which is figure and which is ground (Shukatme, 2001).

1. Proximity: Columns and rows are the main focus here. This principle states that closer to each other things will be seen belonging together.

2. Similarity: This principle states that the things with similar look seen to be belong together.

3. Continuity: Continuity principles indicated the continuous natures of the objects.

4. Closure: These means missing information also can present the figure as whole.

5. Smallness: This means that smaller object can be act as figure against larger background.

6. Symmetry: This principle states that symmetrical objects act as a figure against asymmetrical background.

7. Surroundness: Based on this principle the objects which is surrounding by others can be seen as a figure.

8. Pragnanz: This principles states that in perceiving visual field some objects play as prominent role i.e. figure while some other plays as a background i.e. ground (Soegaard, 2007).

From this above section, Shneiderman's eight golden rules are very important and useful because these present suitable summary of the key principles of interface design and we can use these eight principles during design of the interface as well as during the evaluation process. Gestalt principles describe how we perceive and differentiate figure and ground in the environment. We can apply Gestalt principles of visual perception during the design process because we should consider about several human cognitive processes during the design time of interface. Nielsen ten usability heuristics are very common and useful because these are the general principle guideline for interface design. We can use 
Nielsen ten usability heuristics during the heuristic evaluation of interface design.

\section{CONCLUSIONS}

For good Human Computer Interaction (HCI), usability is very important for accessing computer system without any problem. Lots of rules and guideline we can use for improving the usability of the system. Within these rules and heuristics, Shneiderman's eight golden rules are mostly well-known because it provides a suitable summary of the design process and we can use these rules for design as well as evaluate the interface. Also Nielsen's heuristics rules are useful because it is common to evaluate the interface usability. It is done by multiple experts and at least two passes should be done through the interface. We can also follow the Gestalt principle for visual perception on physical design of interface process because it helps to distinguishes object form the screen and identify the visual elements into groups on the screen.

\section{REFERENCES}

[1]. Dix, A., Finlay, J., Abowd, G. D., Beale, R. (2004) Human-Computer Interaction, 3rd ed. Addison-Wesley Pearson Education, London. pp. 3, 4, 28,191-364

[2]. Hewett, T., Baecker, R., Card, S., Carey, T., Gasen, J., Mantei, M., Perlman, G., Strong, G., \& Verplank, W. (2004) ACM SIGCHI Curricula for Human-Computer Interaction, Available at: < http://sigchi.org /cdg/cdg2.html >

[3]. Olson, G.M. and Olson, J.S. (2003) Human-Computer Interaction: psychological aspects of the human use of computing. Annual Review of Psychology, 54(1), 491-516.

[4]. Zhang, P., Nah, F., \& Preece, J. (2004) HCI studies in Management Information Systems. Behaviour and Information Technology, 23(3), 147-151.

[5]. Hong, J. (2006) Usable Privacy and Security Introduction to HCI Methods [online]. Updated 19 January 2006 [accessed 07 July 2007]. Available from: < http:// cups.cs.cmu.edu/ courses/ups- sp06/notes/060119.pdf $>$.

[6]. Preece, J., Rogers, Y., Sharp, H. (2002) Interaction design: beyond human-computer interaction. John Wiley \& Sons, New York. pp 6, 12, 13, 27, 166

[7]. Saffer, D. (2007) designing for interaction: Creating Smart Applications and Clever Devices. AIGA design press, New York. pp 6-8.

[8]. Holzinger, A. (2005) Usability engineering for software developers. Communications of the ACM, January 29, 2005, 48(1), pp. 71-74.

[9]. Nichols, D.M., McKay, D. \& Twidale, M.B. (2003) Participatory Usability: Supporting Proactive Users. Proceedings of the 4th Annual Conference of the ACM Special Interest Group on Computer Human Interaction, CHINZ'03, Dunedin, New Zealand, 63-68

[10]. Lozano, M., Montero, F., González, P. (2004) A Usability and Accessibility Oriented Development Process. 8th ERCIM Workshop on "User Interfaces For All" (UI4ALL'04), june 2004, Viena, Austria

[11]. Scholtz, J. (2004) Usability Evaluation [online]. [accessed 15 ${ }^{\text {th }}$ September 2007]. Available from: < http:// www.itl. nist.gov/iad/ IADpapers /2004/ Usability\%20Evaluation_rev1.pdf >

[12]. Nielsen, J. (2003) Usability 101: Introduction to Usability [online]. Updated 25 August 2003 [accessed 15 June 2007]. Available from: < http:// www.useit.com/ alertbox/ 20030825. html >.

[13]. Shukatme, S. (2001) Gestalt principles of visual perception Usability [online]. accessed 25 September 2007. Available from: < http://www.artinarch.com/vp12.html > [14]. Soegaard, M. (2007) Gestalt principles of form perception. Retrieved 29 November 2007 from InteractionDesign.org: http:// www. Interaction -design.org/ encyclopedia/gestalt_principles_of_form_p erception.html [15]. Ferre, X., Juristo, N., Windl, H., Constantine, L. (2001) Usability Basics for Software Developers, IEEE Software, January 2001, v.18 n.1, p.22-29. 